\title{
Training Women To Be More Assertive in Mixed-Sex Task-Oriented Discussions ${ }^{1}$
}

\author{
Hedva J. Lewittes ${ }^{2}$ \\ State University of New York, Old Westbury \\ Sandra Lipsitz Bem ${ }^{2}$ \\ Cornell University
}

This study tests the effectiveness of assertiveness training in increasing the level of women's participation in a small mixed-sex task-oriented discussion. Undergraduate women who met both self-descriptive and behavioral criteria for low activity participated with three active undergraduates in a pretest and posttest discussion, each with a different topic and with nonoverlapping group membership, as well as in either an experimental or a control intervention. Experimental subjects received behavioral training in assertiveness while functioning essentially as a fifth member of several tape-recorded discussions. Assertiveness training was successful, with experimental subjects differing from controls on dependent measures reflecting three independent sources of information: (a) the subject's own behavior, as coded by an experimental assistant; (b) pretest and postttest group members' perceptions of the subject's behavior; and (c) the subject's perceptions of her own behavior. These results are interpreted as consistent with the view that a lack of assertiveness in the presence of men-rather than any lack of substantive knowledge or conceptual skill-depresses women's participation in mixed-sex discussions.

\footnotetext{
'This article is based upon a doctoral dissertation by Hedva Lewittes, submitted to the School of Education, Stanford University. The research was supported, in part, by National Institute of Mental Health Grant R01-MH-21735 and, in part, by National Science Foundation Grant BNS-78-22637, both to Sandra L. Bern.

${ }^{2}$ Correspondence should be sent either to Hedva J. Lewittes, Department of Psychology, State University of New York, Box 210, Old Westbury, New York 11568, or to Sandra L. Bem, Department of Psychology, Uris Hall, Cornell University, Ithaca, New York 14853.
} 
In the last few years, a rash of manuals and workshops on assertiveness training for women have appeared on the market (e.g., Bower \& Bower, 1976; Bry, 1975; Butler, 1976; Phelps \& Austin, 1975). These books and workshops attempt to remedy a problem that women's political and consciousness-raising groups have identified (e.g., Bird, 1969; Henley \& Freeman, 1975; Piercy, 1973). In particular, many women feel that they are unable to say what they want to say when they want to say it, particularly in interactions with men. In response to this problem, women seek and therapists employ a barrage of techniques in order to overcome both internalized fears and interpersonal roadblocks.

Empirical evidence on the effectiveness of these techniques has lagged far behind their popular acceptance. In order to narrow the gap, this study devised and tested a training procedure that attempts to increase women's assertiveness in the context of a mixed-sex task-oriented discussion.

Previous research has found that when men and women are together in small task-oriented group discussions, men are more active in the discussion than women, and men also produce a greater number of taskoriented comments. Specifically, men have been found to make a greater number of substantive comments such as suggestions, opinions, and orientations or instructions to the group as a whole; and men have also been found to elaborate and expound more upon their ideas. In contrast, women have been found more likely to produce short incomplete sentences and to defend their ideas with a simple "uh-huh." This sex difference has been found with adults (Nemeth, Endicott, \& Wachtler, 1976; Strodtbeck, James, \& Hawkins, 1958; Strodtbeck \& Mann, 1956; Aries, Note 1; Cooperstein, Note 2; Hall, Note 3), with adolescents (Lockheed, Note 4), and with elementary school children (Zander \& Van Egmond, 1958). Moreover, it has been found even with men and women who are known to have equal levels of professional development and relevant background knowledge (Hall, Note 3). Because this sex difference in overall activity level has not emerged in the context of same-sex interaction (Borgatta \& Stimson, 1963; Lockheed \& Hall, 1976; Cohen, Barchas, Leavitt, \& McMahon, Note 5), it appears to be the presence of men per se-rather than any lack of substantive knowledge or conceptual skill - that depresses women's participation in the context of mixed-sex interaction.

The intervention to be described and evaluated in this article represents an attempt to train women to be more assertive in the context of a mixed-sex task-oriented discussion (i.e., to take the floor when they think they have something to say and to keep the floor long enough to say it persuasively), despite any feelings of lesser status they may have and despite any attempts made to interrupt them. 
Subjects who participated in the experimental intervention were given a rationale for our use of assertiveness training procedures, and they were then provided with the opportunity to practice assertive behaviors. Each subject participated in specified ways as a fifth member of several tape-recorded discussions in which two women and two men came to a decision about various policy-making problems. The procedure was as follows: Each subject listened to active models taken from these tapes; she rehearsed specified assertive behaviors until she reached the criterion; and she received feedback about her performance from the experimenter. When the subject spoke, the experimenter turned off the tape recording until she finished. During the course of the assertiveness training, each subject learned to make comments at frequent predetermined points in the tape-recorded discussion, to respond quickly when given the floor, to speak up first in the discussion, to speak frequently in the discussion at points of her own choosing, to make longer comments, to resist interruption, and to make interruptions at appropriate points in the discussion. In contrast, subjects in the control intervention received no behavioral training. Rather, the control intervention consisted essentially of a "peptalk," which encouraged the subject to become more active in discussions and which was developed in an attempt to control for the unavoidable experimenter demand incorporated into the behavioral intervention.

Although there is no previous research on modifying women's participation in group discussions, the types of training procedures utilized in the experimental intervention (e.g., modeling and behavior rehearsal) are behavioral techniques shown to be successful in increasing assertiveness in two-person interactions (e.g., Gelassi, 1974; Kazdin, 1974; McFall \& Lillesand, 1970; McFall \& Marston, 1970; McFall \& Twentyman, 1973; Rathus, 1973; Twentyman \& McFall, 1975), and also in public-speaking situations (Grossberg, 1965; Krumboltz \& Thoreson, 1969; Lohman, Note 6). (For more comprehensive reviews of assertiveness or "social skills” training, see Bellack \& Hersen, 1977, Rich \& Schroeder, 1976.)

As indicated, the present study was designed to test the effectiveness of assertiveness training in increasing women's participation in a mixedsex small-group discussion. All subjects participated in a pretest and posttest discussion, as well as in either an experimental or a control intervention, with subjects assigned to one or the other of the two interventions on a random basis. It was hypothesized that subjects who participated in the experimental intervention would improve from pretest to posttest significantly more than control subjects in their level of task-oriented participation. It was also hypothesized that this increase in behavioral participation would be great enough to be reflected in the perceptions of the subjects' peers. 


\section{METHOD}

\section{Subjects}

Subjects were 20 female undergraduates at Stanford University in 1975 who demonstrated in two different ways that they did not participate actively in mixed-sex group discussions: (a) They responded to a sign-up sheet asking for women who feel that they do not speak enough in mixedsex discussions and would like to be trained to become more active in that context; and (b) they met a behavioral criterion for low participation in a four-person pretest discussion (i.e., they ranked either third or last both in the percentage of substantive "acts" that they produced and in the percentage of time that they spoke).

All of the women who responded to the sign-up sheet were randomly assigned either to the experimental (assertiveness training) group or to the control group prior to being contacted by the experimenter. When contacted, they were scheduled for their pretest discussion. They were unaware that their performance during the pretest discussion could be used to disqualify them from further participation in the study. Like all the other members of the group, they were simply encouraged to be as active as possible.

\section{Pretest and Posttest Discussion}

Both the pretest and the posttest consisted of four-person mixedsex discussions. Each group included one female subject as well as three "participants," one of whom was a woman and two of whom were men. These participants were also Stanford undergraduates, but had signed up on a sheet asking for people who enjoy being active and who are active in group discussions. For each subject as well as for each participant, there was no overlap between the three other members of the pretest and posttest groups. Thus, no one in the study ever interacted with the same person more than once, and no subject ever interacted with any other subject. The participants had no idea that the discussions were part of an assertiveness training project; they were also unaware that one of the group members (the subject) held a special status and had been recruited by a quite different procedure.

At the start of both the pretest and the posttest discussions, a female research assistant gave the group a preselected topic to discuss, and she instructed the four members to be as active as possible and to reach a decision within about 20 minutes. A different topic was presented for 
discussion during the pretest and posttest, with the order of presentation counterbalanced across experimental and control subjects. Both topics were of a policy-making nature and required a task-oriented discussion. One asked subjects to act as members of an editorial board on a student newspaper who had to decide how to deal with an advertiser who felt that their news coverage of Vietnam was not objective; the other asked the group to recommend to the university how an empty building should be used.

\section{The Experimental Intervention}

The experimental intervention began with a brief talk which acquainted subjects with the assumptions underlying our decision to utilize assertiveness training and which included a discussion of the relationship between women's low participation in mixed-sex groups and women's position in society. Subjects then participated in three assertiveness training sessions, each lasting approximately one hour. The same procedures were used throughout to teach the subjects various assertive behaviors. For each new behavior, the experimenter would clarify the goal and the subject would then listen to a tape-recorded model. The experimenter would then label and evaluate the model's behavior, instruct the subject how to practice, and inform the subject of how many responses the criterion required. With the help of feedback from the experimenter, the subject would rehearse the behavior until she reached criterion. While rehearsing, the subject would function essentially as a fifth member of a tape-recorded four-person mixed-sex discussion, and the experimenter would simply turn off the tape recorder whenever the subject spoke.

Although interacting with a tape recorder may seem contrived, subjects adjusted quite easily and became quite involved in the discussions. Moreover, the tapes were excellent tools for behavior rehearsal because they included the same verbal cues as live discussion, but without the associated threat or pressure. Subjects could not actually be judged or pressured by the group; they could stop the tape and take time to think before responding; and they could practice skills before the skills were fully perfected. In all, subjects participated in tape-recorded discussions of nine different policymaking topics during the assertiveness training, each with a different set of group members.

In the first session, the subject was trained to respond frequently and with a short latency. The experimenter began by turning off the tape at predetermined points in the discussion and leaving the tape off until the subject responded. After achieving a criterion of 10 complete responses out of 12 breaks, the subject was required to make 5 complete responses with a 
two-second latency, a one-second latency, and a half-second latency, respectively.

In the second session, the subject practiced speaking up first in the discussion by presenting her ideas on the topic before the tape began. The subject also learned to speak frequently at points in the discussion of her own choosing. The subject was instructed to begin speaking whenever she wished and felt it was appropriate, at which time the experimenter would turn off the tape recorder. After reaching the criterion of five selfinitiated comments in five minutes, the subject practiced making longer comments until she reached the criterion of three additional self-initiated comments, each at least one minute long.

In the third session, the subject learned to resist and to make interruptions. When the subject started to speak, the experimenter turned off the tape recorder, but then turned it back on before the subject had finished. Afther successfully resisting interruption six times by raising her voice and continuing to talk until the tape recorder was turned off again, the subject practiced making interruptions when a particular speaker was monopolizing the discussion. Subjects were instructed to start talking rather loudly when the particular speaker was in midsentence or midthought and to continue talking until the tape recorder was turned off. Subjects were encouraged to interrupt only when it was necessary to do so in order to get the floor, and they practiced this behavior in a tape-recorded discussion that was completely dominated by one male participant. At the end of the third training session, the subject was informed that she would soon be participating in another live discussion group, and she was explicitly instructed to apply all the skills she had practiced to this new discussion.

\section{The Control Intervention}

Although the experimental intervention was explicitly designed to teach specific behavioral skills, the procedures introduced a number of additional elements which, might be considered potentially responsible for any behavior change that would occur - for example, the positive value placed on women's active participaton; the rapport between the subject and experimenter, and, perhaps most importantly, the strong expectation of the experimenter that the subject could and would change her behavior. Accordingly, a procedure was developed in an attempt to control for the effects of these "demand" characteristics.

In the control condition, the experimenter presented a pep-talk, which was, by and large, simply an expanded version of the same introductory remarks presented in the experimental condition. That is, the experimenter argued that a woman's low participation in mixed-sex discussions is not just her own personal problem, but a result of women's lower status in American society and of the socialization process. More- 
over, the experimenter made clear that she placed a high value on a woman's becoming more assertive and that she also felt the subject had sufficient knowledge and discussion skill to be far more active than she was accustomed to being. In addition, however, the control experimenter also went on the suggest that the subject could increase her level of participation with just a little more effort and courage. The talk ended with an explicit statement telling the subject that, in the discussion to come, she ought to try to be "as active, talkative, and assertive" as she possibly could.

The control procedure lasted approximately 30 minutes and was run by the same female experimenter who ran all of the assertiveness training sessions (the senior author). Although the total amount of interaction between experimenter and subject was far less than in the experimental intervention, every effort was made to develop a strong rapport between the two principals and also to convey the experimenter's strong expectation that the subject could and would change her behavior.

\section{Dependent Variables}

Both the pretest and posttest discussions were recorded and were later scored by the same female research assistant who had been present during the discussion. The research assistant was blind to which member of the group was the subject, whether the subject had been assigned to the experimental or the control intervention, and whether the discussion constituted a pretest or a posttest. There were five research assistants, none of whom ever instructed or scored any group member more than once.

The research assistant assigned to a particular pretest or posttest discussion coded every statement by every member of the group for whether it was or was not a substantive "act"; an "act" was defined as an uninterrupted speech by an actor, including pauses, which expresses a complete thought and which is relevant to the solution of the problem (Hall, Note 3). Acts included suggestions, opinions, ideas, evaluations, directions to the group, analyses, and clarifications. One-word responses and unexplained phrases, such as "Yeh," "Uh-huh," and "I disagree," were considered nonsubstantive and were therefore not included in the definition of an act. In order to assess the reliability of coding acts, all five coders independently scored two tapes - one at the end of their initial training period and the other at the end of the research-and a correlation was computed across all possible pairs of coders. The scoring of acts proved to be highly reliable at both times $\left(r=.94\right.$ and .88 , respectively). ${ }^{3}$

\footnotetext{
${ }^{3}$ An attempt was also made to code successful and unsuccessful interruptions by each subject (successful interruptions $r=.75$ and .71 , respectively; unsuccessful interruptions $r=$ .44 (followed by additional training) and .81 , respectively). Because the number of interruptions by both subjects and participants was exceedingly small, there will be no further discussion of either successful or unsuccessful interruptions in this article.
} 
Three other behavioral measures were also scored from the tapes: (a) the total amount of time taken by each group member, (b) the mean length of each subject's acts, and (c) whether or not the subject was the first to speak in the discussion. It will be recalled that a subject was required to rank third or last during the pretest discussion in both the percentage of total acts produced and in the percentage of total speaking time, in order to be allowed to participate further in the research.

At the end of both the pretest and the posttest discussions, all group members, including the subject, filled out a questionnaire which asked them to rank each other and themselves on three behavioral dimensions: (a) how active they were, how many comments they made, and how much group time they took up; (b) how much of a contribution they made to the discussion and to the final decision; and (c) how much they did to keep relationships between group members cordial and friendly. In addition, all persons also indicated how much they liked every other member of the group, and how much they perceived themselves as being liked by the group as a whole. Finally, the experimental and control subjects (but not the participants) also filled out a questionnaire asking them to compare their own pretest and posttest performances.

\section{RESULTS}

\section{Behavioral Measures}

The most important behavioral measure in this study is the percentage of total acts in the pretest and posttest discussions produced by the subject. An act, it will be recalled, is an uninterrupted speech by an actor which expresses a complete thought and which is relevant to the solution of the problem. Table I presents the percentage of acts produced by the experimental and control subjects on both the pretest and posttest, as well as the amount of pretest-to-posttest change for both groups. As Table I shows, there was no significant difference between the two groups prior to training, a result which follows directly from the random assignment

Tahle I. Mean Percentage of Total Acts in Group Discussion

\begin{tabular}{lccc}
\hline & Experimental & Control & $t$ \\
\hline Pretest & 14.9 & 17.4 & $<1$ \\
Posttest & 27.8 & 18.4 & $2.87^{a}$ \\
Pretest-to-posttest change & 12.9 & 1.0 & $2.58^{a}$ \\
\hline${ }^{a} p<.005$. & & &
\end{tabular}


of subjects to conditions. As can also be seen, the two groups were quite different after training, with experimental subjects increasing significantly more from pretest to posttest than control subjects, $t(18)=$ $2.58, p<.005$, and with experimental subjects also producing a significantly higher percentage of acts on the posttest than did control subjects, $t(18)=2.87, p<.005 .^{4}$

The same pattern of results was found for the percentage of total speaking time. On this variable as well, the experimental subjects increased significantly more from pretest to posttest than did the control subjects, $t(18)=1.84, p<.04$, and the former subjects also spoke significantly more on the posttest, $t(18)=1.80, p<.04$. The control subjects increased their pretest rate only by half - from $11.9 \%$ to $17.8 \%$ while the experimental subjects more than doubled their pretest ratefrom $11.1 \%$ to $25.5 \%$.

The results for these two measures thus indicate that the experimental intervention succeeded in its major goal of increasing the overall level of women's participation in the context of a mixed-sex discussion. In addition, the experimental intervention was also successful in training one particular behavioral tactic, namely, speaking up first in the posttest discussion. Thus, no single experimental subject and only one control subject had spoken up first in the pretest discussion, but nine experimental subjects spoke up first in the posttest discussion compared, still, to only one control subject. This difference on the posttest was highly significant, $\chi^{2}=9.8, p<.005$.

In contrast, the experimental intervention was less successful in training the tactic of producing longer acts. With respect to the mean length of a subject's acts, thcre was no significant difference between the experimental and control groups on either the pretest or the posttest, nor did the groups differ significantly in their pretest-to-posttest change. However, the experimental group increased significantly from pretest to posttest even on this variable, $t(9)=3.15, p<.005$; the control group did not.

Taken as a whole, the results for the behavioral measures indicate that the experimental intervention was successful in increasing the overall level of women's participation in the posttest discussion. We turn now to a discussion of the participants' rankings of the subjects on various questionnaire items in order to assess whether the experimental subjects' increase in behavioral participation was great enough to be perceived by their peers and to be reflected in their rankings.

\footnotetext{
${ }^{4} \mathrm{All}$ probability levels reported are based upon one-tailed tests of statistical significance. For all dependent measures, the same pattern of significant findings is obtained when the differences between the experimental and control subjects on the posttest are analyzed by means of analysis of covariance, with the subject's pretest score treated as a covariate.
} 
Table II. Participants' Mean Rankings of Subjects' Par-

\begin{tabular}{lccc}
\multicolumn{4}{c}{ ticipation } \\
\hline & Experimental & Control & $t$ \\
\hline Pretest & 3.70 & 3.57 & $<1$ \\
Posttest & 2.38 & 3.16 & $2.18^{a}$ \\
Pretest-to-posttest change & 1.32 & .41 & $2.11^{\alpha}$ \\
\hline
\end{tabular}

${ }^{a} p<.025$.

\section{Participants' Perceptions}

All group members, subjects and participants alike, ranked themselves and each other at the end of both the pretest and posttest discussions on three behavioral dimensions: (b) how active they were and how much group time they took up (i.e., "most," "second," "third," and "least"); (b) how much of a contribution they made to the discussion and to the final decision; and (c) how much they did to keep relationships between group members cordial and friendly. Only the participants' rankings of the experimental and control subjects will be considered in this section.

Because the participants' activity and contribution rankings were highly correlated $(r=.78)$, these two items were averaged together into a single measure reflecting the subject's general level of participation as perceived by the participants in her group. The third item was not highly correlated with either of the other two (Activity $r=.16$; Contribution $r=.23$ ), however. Accordingly, it was taken more specifically to reflect the subject's expressive role in the group and was analyzed separately.

Table II presents the mean pretest rankings, posttest rankings, and pretest-to-posttest change scores for the combined "perceived participation" measure. As can be seen in Table II, the increase in behavioral participation by the experimental subjects was reflected in the participants' rankings. Thus, although there was no significant difference between the groups prior to training, the two groups were quite different after training. Specifically, the experimental group was perceived as increasing in participation from pretest to posttest significantly more than the control group, $t(18)=2.11, p<.025$, and the former group was also perceived as participating significantly more than the control group on the posttest itself, $t(18)=2.18, p<.02 .^{5}$

\footnotetext{
${ }^{5}$ Although the high correlation between participants rankings of activity and contribution necessitated the construction of a single measure reflecting the subject's general level of participation as perceived by the participants in her group, it is interesting to note that the difference between experimental and control subjects in the amount of pretest-to-posttest change was actually greater for subject's contribution, $t(18)=2.74, p<.01$, than for subject's activity, $t(18)=1.38, n s$.
} 
In contrast to the combined rankings for activity and contribution, participants' rankings of how much individuals did to keep relationships between the group members friendly and cordial revealed no significant differences between the experimental and control groups on the pretest, $t(18)<1, n s$, on the posttest, $t(18)=1.21, n s$, or in the amount of pretest-to-posttest change, $t(18)<1$, ns. Moreover, neither the experimental nor the control group changed significantly from pretest to posttest, experimental $t(9)=1.19, n s$; control $t(9)<1, n s$. It will be recalled that the experimental intervention was not designed to increase this type of behavior. Rather, we hoped to increase the subjects' task-oriented contribution without decreasing their level of social supportiveness.

Finally, it will be recalled that each participant also indicated which other person in the group he or she liked "best," "next best," and "least." Although there were no significant differences in how well liked experimental and control subjects were on the pretest, $t(18)<1, n s$, experimental subjects were liked significantly more than control subjects on the posttest, $t(18)=1.91, p<.04$.

The results of the participants' rankings indicate that the behavioral change by the experimental subjects was sufficient to be perceived by the members of the pretest and posttest groups, respectively. We turn now to a discussion of the extent to which the subjects perceived a change in their own behavior.

\section{Subjects' Perceptions}

The data on the subjects' perceptions come from two sources: (a) subjects' rankings of themselves on the above four questions just discussed from the point of view of the participants (the subject's level of activity, contribution, etc.); and (b) subjects' ratings of the amount of change they perceived from pretest to posttest in seven specified behaviors.

As indicated, the participants' rankings of activity and contribution were highly correlated $(r=.78)$; therefore, these rankings were averaged together into a single measure reflecting the subject's overall level of participation as perceived by her peers. In contrast, subjects' rankings of activity and contribution were only moderately correlated $(r=.46)$, so that their self-perceptions of these two items were analyzed separately. Consistent with this lower correlation is the observation that a number of subjects spontaneously generated the activity/contribution distinction during training, expressing concern that the training procedure might increase their activity level without simultaneously increasing their ability to make a meaningful contribution to the discussion and to the final decision. 
Table III. Subject's Self-Rankings of Their Contribution

\begin{tabular}{lccc}
\hline & Experimental & Control & $t$ \\
\hline Pretest & 3.20 & 2.80 & $<1$ \\
Posttest & 2.00 & 2.60 & $1.77^{a}$ \\
Pretest-to-posttest change & 1.20 & .20 & $2.06^{a}$ \\
\hline${ }^{a} p<.05$. & & &
\end{tabular}

In fact, the experimental and control groups differed only in how much of a contribution they perceived themselves as making. Table III presents the mean pretest rankings, posttest rankings, and pretest-toposttest change scores for subjects' self-rankings on contribution; as can be seen, there were no significant differences between the groups on the pretest, $t(18)<1$, ns. As can also be seen in Table III, the experimental subjects changed significantly more from pretest to posttest than did the control subjects, $t(18)=2.06, p<.03$, and the former also ranked themselves significantly higher than the control subjects on the posttest, $t(18)=1.77, p<.05$. In contrast, there were no significant differences between the groups in their self-rankings of how active they were, how much they had done to keep relations between group members cordial and friendly, or how much they were liked by others.

As indicated above, subjects also rated on a 7-point scale the amount of behavior change they perceived from pretest to posttest on the following seven specified behaviors: (a) the number of comments they made, (b) the length of their comments, (c) the amount of evidence and support they gave to their own ideas, (d) the number of comments directed to them, (e) the amount others listened to them and considered their ideas, (f) the number of interruptions they made, and $(\mathrm{g})$ the number of interruptions they resisted. In fact, the results indicated that the experimental subjects perceived themselves as having changed significantly more than the control subjects on three of these dimensions: (a) the length of their comments, $t(18)=2.41, p<.02$; (b) the number of comments others directed to them, $t(18)=3.38, p<.002$; and (c) the number of interruptions they made, $t(18)=2.94, p<.005$.

In light of these perceptions by the subject, it would have been extremely interesting to have had an independent assessment of the number of comments directed to the subject, but audio-recordings do not lend themselves to this type of analysis. As noted, however, behavioral coding of the group discussions revealed no significant differences between the experimental and control groups, either in the length of their comments or in the number of interruptions that they made. ${ }^{6}$

${ }^{6}$ Experimental and control subjects also rated the perceived effectiveness of their respective training procedures at the very end of their training (i.e., before the posttest discussion 


\section{DISCUSSION}

As indicated in the introduction to this article, the decision to utilize an assertiveness training procedure in order to increase women's participation in mixed-sex discussions was based on a particular theoretical assumption: Women do not participate as much as men-when men are present-because they lack the assertiveness both to take the floor when they think they have something to say and to keep the floor long enough to say it persuasively.

In fact, the assertiveness training procedures employed in this study were successful, with experimental and control subjects differing significantly on dependent variables reflecting three independent sources of information: (a) the subject's own behavior, as coded by an experimental assistant; (b) participants' perceptions of the subject's behavior; and (c) the subject's perceptions of her own behavior. The converging of all three sources of data is testimony not only to the effectiveness of the procedures employed but also to the theoretical perspective upon which these procedures are based.

Moreover, no negative "side-effects" appear to have been associated with the experimental intervention, despite the following three plausible possibilities: (a) Training women to be more actively task oriented might simultaneously lead to an unintended decrease in their level of social supportiveness; (b) simply training women to be more active-without simultaneously teaching them substantive knowledge or conceptual skills - might lead them to speak when they had nothing of substance to say and thereby to make no substantive contribution to the group; and (c) because it is considered inappropriate or unfeminine for a woman to be active and assertive in the context of a mixed-sex discussion, becoming more active and assertive in that context might be associated with a decrease in popularity.

With respect to the first of these concerns - that assertiveness training might lead women to be less socially supportive - participants' rankings of how much individuals did to keep relationships between the group members friendly and cordial revealed no significant pretest-to-posttest change

occurred). Experimental and control subjects differed significantly on two of the three items, with experimental subjects expressing more confidence in their ability to talk effectively in a group as a result of training, $t(18)=2.63, p<.01$, and with experimental subjects also rating their training as more effective in enabling them to be more active in discussions, $t(18)=2.23, p<.02$. The difference between the groups was marginally significant on the third item as well, with experimental subjects feeling that they would be more talkative in future discussions as a result of the training, $t(18)=1.69, p<.06$. Not surprisingly, then, the difference in ultimate effectiveness between the experimental intervention and its control was anticipated by the subjects prior to the occurrence of the posttest discussion. 
for either the experimental or the control groups, nor did these results reveal any significant differences between the two groups. With respect to the second of these concerns - that assertiveness training might lead women to speak when they had nothing of substance to say-participants' rankings of activity and contribution were highly correlated; furthermore, experimental subjects increased from pretest to posttest significantly more than control subjects on a measure which incorporated both of these variables; and, finally, the difference between experimental and control subjects was actually greater in participants' rank-ordering of who "made a contribution to the discussion and to the final decision" than in their rank-ordering of who "made the most comments and took up most group time." Finally, with respect to the last of these concerns - that assertiveness training might lead women to be less liked-although there were no significant differences in how well liked experimental and control subjects were on the pretest, experimental subjects, were liked significantly more than control subjects on the posttest. Thus, in contrast to some of our subjects' worst fears, no negative side-effects appeared to be associated with assertiveness training.

Taken as a whole, then, the results of this study document the effectiveness of the assertiveness training procedures employed here to increase women's participation in mixed-sex task-oriented group discussions. In addition, the behavior change occurred in a setting which was both more lifelike and more rigorous than the usual situations used to evaluate assertiveness training procedures. In particular, the pretest and posttest participants were entirely nonoverlapping and were also not confederates; entirley different topics were discussed during the pretest, posttest, and training period; and the discussions were live and spontaneous.

Even so, two features of the current study limit the generalizability of the results to the real world. First, the pretest and posttest discussions were strikingly noncompetitive, with all group members explicitly instructed to work together to reach consensus. Becoming more active might be both more difficult and more costly in terms of popularity if the situation were more competitive. Even more important, our subjects all entered the posttest discussions as unknown quantities presumed equal to everyone else by their peers. In the context of an ongoing group in the real world, however, any change in behavior by an individual must be sufficient not only to define oneself "from scratch" as an active participant but also to overcome negative stereotypes and expectations produced in the minds of others by one's own past history of nonparticipation.

It should be clear that the purpose of this study was to assess whether the experimental intervention as a whole was effective. Because the experimental intervention was quite complex, we cannot specify with any precision which components were critical or how much each component 
contributed to the behavior change that occurred. For example, the experimental intervention explicitly identified and labeled a set of assertive behaviors (e.g., speaking first, resisting interruptions) while simultaneously training subjects to perform these behaviors. The results of this study indicate quite clearly that the experimental intervention was effective as a whole; additional research would be required to tease apart the particular contribution made by each aspect of the training procedure.

\section{REFERENCE NOTES}

1. Aries, E. Interaction patterns and themes of male, female, and mixed groups. Paper presented at the annual meeting of the American Psychological Association, New Orleans, 1974.

2. Cooperstein, R. A. Mixed-sex group interaction: The effects of sex-role traditionalism and ability expectations. Unpublished doctoral dissertation, Department of Psychology, Stanford University, 1978.

3. Hall, K. P. Sex differences in initiation and influence in decision-making among prospective teachers. Unpublished doctoral dissertation, School of Education, Stanford University, 1972.

4. Lockheed, M. E. The modification of female leadership behavior in the presence of men. Final report to the National Institute of Education, October, 1976. (ERIC Document Reproduction Service No. ED 159493 )

5. Cohen, E. G., Barchas, P. R., Leavitt, H. J., \& McMahon, A. M. Power and authority in female work groups. Unpublished manuscript, School of Education, Stanford University, 1975.

6. Lohman, M. Changing a racial status ordering by means of role modeling (Technical Report No. 3). School of Education, Stanford University, 1970.

\section{REFERENCES}

Bellack, A., \& Hersen, M. Social skills training. In Behavior modification. Baltimore: Williams \& Wilkins, 1977.

Bird, C. Born female. New York: Simon \& Schuster, 1969.

Borgatta, E. G., \& Stimson, J. Sex differences in interaction characteristics. Journal of Social Psychology, 1963, 60, 89-100.

Bower, S., \& Bower, G. H. Asserting yourself. Reading, Mass.: Addison-Wesley, 1976.

Bry, E. Coping: breaking out of the mold. California Living Magazine: San Francisco Examiner and Chronicle, August 3, 1975, pp. 20-21.

Butler, P. Self-assertion for women. San Francisco: Canfield Press, 1976.

Gelassi, J., Felassi, M., \& Litz, C. Assertive training in groups using video feedback. Journal of Counseling Psychology, 1974, 21, 390-394.

Grossberg, J. Successful behavior therapy in a case of speech phobia. Journal of Speech and Hearing Disorders, 1965, 30, 285-288.

Henley, N., \& Freeman, J. The sexual politics of interpersonal behavior. In J. Freeman (Ed.), Women: A feminist perspective. Palo Alto: Mayfield, 1975.

Kazdin, A. E. Effects of covert modeling and model reinforcement on assertive behavior. Journal of Abnormal Psychology, 1974, 83, 240-252. 
Krumboltz, J., \& Thoreson, C. Behavioral counseling: Cases and techniques. New York: Holt, Rinehart \& Winston, 1969.

Lockheed, M. E., \& Hall, K. P. Conceptualizing sex as a status characteristic: Applications to leadership training strategies. Journal of Social Issues, 1976, 32, 111-124.

McFall, R., \& Lillesand, D. Behavior rehearsal with modeling and coaching in assertion training. Journal of Abnormal Psychology, 1970, 77, 313-323.

McFall, R., \& Marston, A. An experimental investigation of behavior rehearsal in assertion training. Journal of Abnormal Psychology, 1970, 76, 295-303.

McFall, R., \& Twentyman, Four experiments on the relative contribution of rehearsal, modeling and coaching to assertion training. Journal of Abnormal Psychology, 1973, 81, 199-218.

Nemeth, C., Endicott, J., \& Wachtler, J. From the ' 50 's to the ' 70 's: Women in jury deliberations. Sociometry, 1976, 39, 293-304.

Piercy, M. Unlearning to not speak. To be of use. New York: Doubleday, 1973.

Phelps, S., \& Austin, N. The assertive woman. San Luis Obispo, Calif.: Impact Publishers, 1975.

Rathus, S. Instigation of assertive behavior through videotape mediated assertive models and directed practice. Behavior Research and Therapy, 1973, 11, 57-65.

Rich, A. R., \& Schroeder, H. E. Research issues in assertiveness training. Psychological Bulletin, 1976, 83, 1081-1096.

Strodtbeck, F. L., James, R. M., \& Hawkins, C. Social status in jury deliberations. In E. E. Maccoby, T. M. Newcomb, \& E. L. Hartley (Eds.), Readings in social psychology, New York: Holt, Rinehart \& Winston, 1958.

Strodtbeck, F. L., \& Mann, R. D. Sex role differentiation in jury deliberations. Sociometry, 1956, 19, 3-11.

Twentyman, C., \& McFall, R. Behavioral training of social skills in shy males. Journal of Consulting and Clinical Psychology, 1975, June, 43, 3, 384-395.

Zander, A., \& Van Egmond, E. Relationship of intelligence and social power to the interpersonal behavior of children. Journal of Educational Psychology, 1958, 49, 256-268. 